\title{
MASS DISTRIBUTIONS OF GALAXIES WITH GLOBULAR CLUSTER SYSTEMS
}

\author{
Kazutomo Takayanagi \\ Ryukoku University and Kyoto University
}

Density curves of polytrope index 5 were fitted to the surface density distributions of 26 globular cluster systems. Though we have shown only two of them in Fig. 1, the remaining systems resemble the above cases. No differences exist between elliptical and spiral

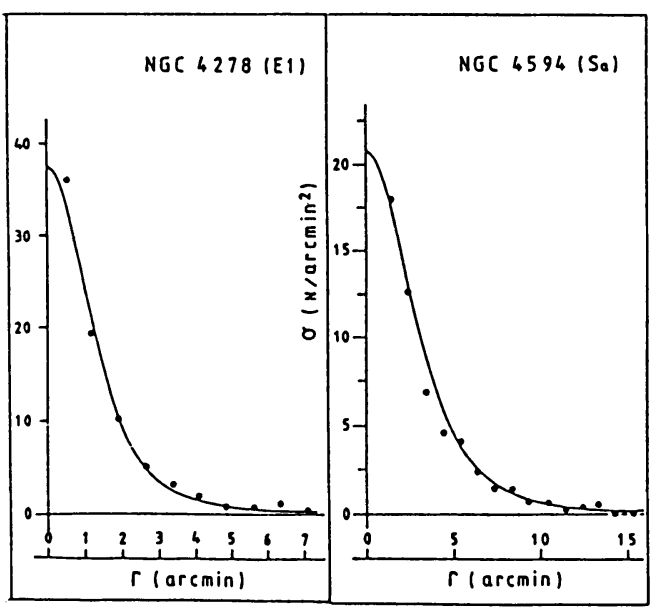

Fig. 1. Surface density distributions of globular cluster systems with the best fit of the polytropes (solid lines). galaxies.

If we can regard the globulars associated with a galaxy as tracers of mass distribution of the parent galaxy, this can be represented by that of the globular cluster system in spite of some discrepancy between the mass and the brightness distributions.

Assuming that the density distributions of the galaxies with globular cluster systems can be represented by those of the polytrope of index 5, we obtained masses of the galaxies by putting central velocity dispersions of these galaxies in the following formula;

$$
m=\sqrt{3} \alpha^{3} \rho_{c}=\left(2 \sqrt{3} \alpha \overline{V_{p}^{2}}\right) / G
$$

where $\alpha$ is a scale factor which is obtained in the process of the fit mentioned above.

The results have been shown in Table 1. Masses of twelve ellipticals and one spiral ( $\mathrm{Sa}$ ) are order of $10^{12} \mathrm{~m}_{\bullet} . \quad M 87$ is the most massive galaxy even in this study.

The masses obtained above and the various physical parameters which have been taken from catalogs and lists in other papers have been combined to examine the correlations among them though only tro of

639

J. E. Grindlay and A. G. Davis Philip (eds.),

The Harlow-Shapley Symposium on Globular Cluster Systems in Galaxies, 639-640.

(C) 1988 by the IAU. 
them have been shown in Fig. 2, all the correlations obtained and their least square solutions are as follows;

Table 1

Masses of the galaxies

with the globular cluster systems.

\begin{tabular}{|c|c|c|c|c|}
\hline $\begin{array}{l}\text { GALAXY } \\
\text { (NGC) } \\
(1)\end{array}$ & $\begin{array}{c}\alpha \\
(2)\end{array}$ & $\begin{array}{c}\overline{V_{\mathrm{m}}^{2}} \\
(3 / \mathrm{s}) \\
(3)\end{array}$ & $\begin{array}{c}d \\
\left(\begin{array}{c}d P C \\
(4)\end{array}\right.\end{array}$ & $\begin{array}{c}\text { MASS } \\
\left(10^{\circ 9} \mathrm{mal}\right. \\
(5)\end{array}$ \\
\hline $\begin{array}{r}224 \\
524 \\
1052 \\
1399 \\
2683\end{array}$ & $\begin{array}{l}3.333 \\
1.186 \\
0.800 \\
0.841 \\
1.360\end{array}$ & $\begin{array}{r}166 \\
270 \\
204 \\
* 250 \\
142\end{array}$ & $\begin{array}{l}0.66 \\
43 \\
24 \\
22 \\
22\end{array}$ & $\begin{array}{r}22 \\
260 \\
56 \\
81 \\
15\end{array}$ \\
\hline $\begin{array}{l}3226 \\
3311 \\
3377 \\
3379 \\
3607\end{array}$ & $\begin{array}{l}0.597 \\
1.565 \\
0.976 \\
0.800 \\
0.733\end{array}$ & $\begin{array}{r}207 \\
* 250 \\
160 \\
218 \\
240\end{array}$ & $\begin{array}{l}20 \\
55 \\
10 \\
13 \\
14\end{array}$ & $\begin{array}{r}36 \\
380 \\
18 \\
35 \\
42\end{array}$ \\
\hline $\begin{array}{l}4278 \\
4374 \\
4406 \\
4472 \\
4486\end{array}$ & $\begin{array}{l}1.155 \\
2.121 \\
3.259 \\
2.213 \\
3.983\end{array}$ & $\begin{array}{l}243 \\
296 \\
256 \\
315 \\
335\end{array}$ & $\begin{array}{l}14 \\
20 \\
20 \\
20 \\
20\end{array}$ & $\begin{array}{r}68 \\
260 \\
300 \\
310 \\
610\end{array}$ \\
\hline $\begin{array}{l}4526 \\
4565 \\
4594 \\
4621 \\
4636\end{array}$ & $\begin{array}{l}2.757 \\
1.302 \\
2.706 \\
2.684 \\
2.673\end{array}$ & $\begin{array}{l}275 \\
136 \\
256 \\
225 \\
217\end{array}$ & $\begin{array}{l}20 \\
20 \\
20 \\
20 \\
20\end{array}$ & $\begin{array}{r}290 \\
34 \\
250 \\
190 \\
180\end{array}$ \\
\hline $\begin{array}{l}4649 / \\
4697 \\
5128 \\
5813 \\
5846\end{array}$ & $\begin{array}{l}3.596 \\
1.788 \\
4.904 \\
0.949 \\
1.163\end{array}$ & $\begin{array}{r}344 \\
186 \\
* 100 \\
281 \\
250\end{array}$ & $\begin{array}{l}20 \\
20 \\
5.0 \\
31 \\
29\end{array}$ & $\begin{array}{r}600 \\
87 \\
17 \\
110 \\
150\end{array}$ \\
\hline Galaxy & 3.142 & $* 137$ & 11 & 14 \\
\hline
\end{tabular}

(1) $\log \mathrm{N}_{\mathbf{t}}=0.91 \log \mathrm{m}-7.9$

(2) $\log m=0.89 \log D_{y}^{3}+8.3$

(3) $\log m=-0.51 M_{B}+1.2$

(4) $\log \mathrm{N}_{t}=-0.37 \mathrm{MB}_{\mathrm{B}}-4.9$

(5) $\log N_{t}=0.014 R_{Q}+2.4$

(6) $R_{G}=2.3 D_{g}-12$

(7) $\log N_{t}=0.70 \log D_{q}^{3}+0.032$

(8) $\mathrm{m} / \mathrm{L}_{\mathrm{B}}=0.10+14$

(9) $M_{B}=-1.8 \log D_{8}^{3}+14$

where $\mathrm{Dg}$ means a geometrical mean of the major and the minor axis of the parent galaxy and $R_{Q}$ is the radius of the cluster system derived from the density curve.

We showed that the mass distributions of galaxies fit well the distributions of polytrope index 5 . This fact suggests that the mass distributions of galaxies (halos) have been formed in the gas stage because the form of the polytropic density distribution is thought to be the result of collisions of the elementary particles of which it made.
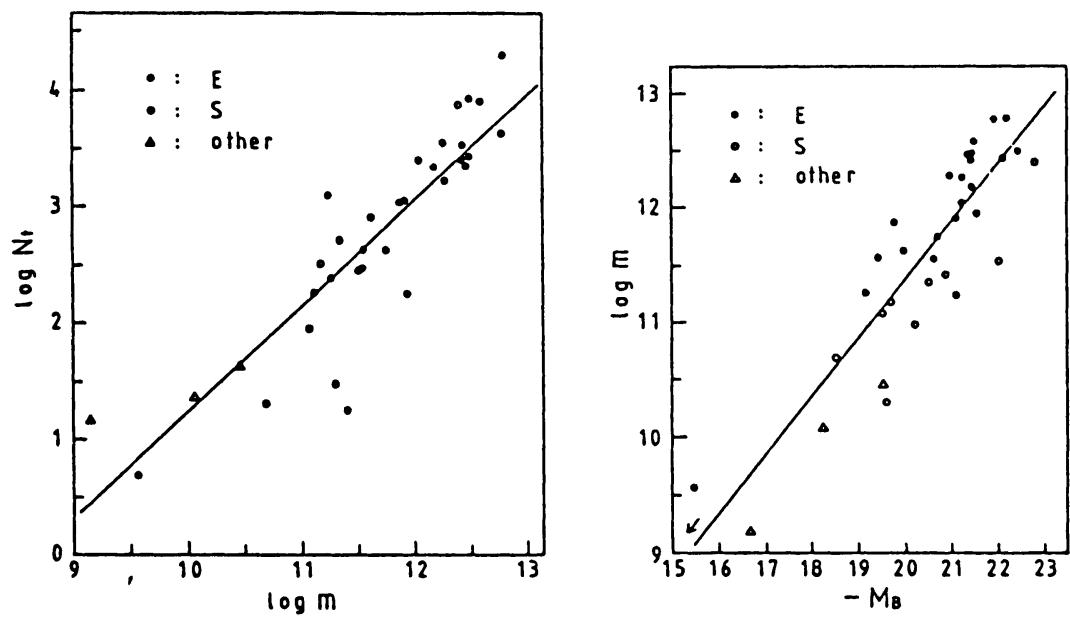

Fig. 2. Correlations of physical parameters included in our work. 